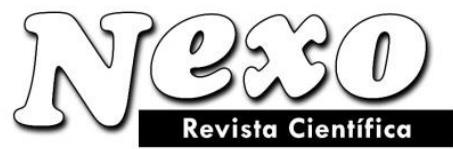

\title{
Modeling of the components of the natural environment
}

\author{
Modelado de los componentes del medio natural
}

\author{
Evgeny Kuznetsov ${ }^{1 *}$, Anna Khadzhidi ${ }^{1}$, Margarita Kuznetsova ${ }^{1}$, Sergey Pushenko ${ }^{2}$ \\ ${ }^{1}$ Kuban State Agrarian University named after I.T. Trubilina, 13, Kalinina str, Krasnodar, Russia \\ ${ }^{2}$ Don State Technical University, 1, Gagarin sq., 344003, Rostov-On-Don, Russia
}

(recibido/received: 19-mayo-2021; aceptado/accepted: 10-agosto-2021)

dtn-khanna@yandex.ru

\begin{abstract}
The article substantiates the management of the agroresource potential of agricultural landscapes $(A R P A)$ by an integral risk indicator on a digital platform in the Google system to improve the reclamation state of soils. The digital platform for managing the agroresource potential is located in the Hilbert separable space vector field. Management of the agroresource potential proceeds along with a change in the intensity of the energy flow of the substance, which is formed from the use of melioration techniques Energy affects the land reclamation state $(L R S)$ of the agricultural landscape. It has a significant impact on the integral indicators of resource risks. To assess the reclamation state of the agricultural landscape, a critical risk indicator (IIR) has been developed, a resource risk model, which is a simulation and resource model, as it combines various quantitative indicators of LRS with dimensionless risk indicators and determines the critical state of the resource. The base of the computer program contains a resource risk model $I I R$, which includes risk indicators and the risk safety scale (SSR), which makes it possible to assess the resource potential of the agricultural landscape. The IIR model is adapted to the natural resources of a real agricultural landscape. The basis of the model is the resource risks $L R S$, with the help of which the management of the reclamation state of the farming landscape is carried out. Optimization of the integral risk indicator for taxa resources reduces the volume of work performed by reclamation techniques.
\end{abstract}

Keywords: agrolandscape, method, program, management, soil reclamation state.

\section{RESUMEN}

El artículo fundamenta la gestión del potencial de recursos agrícolas de los paisajes agrícolas (ARPA) mediante un indicador de riesgo integral en una plataforma digital en el sistema de Google para mejorar el estado de recuperación de suelos. La plataforma digital para gestionar el potencial de fuentes agrícolas se encuentra en el campo de vectores espaciales separables de Hilbert. La gestión del potencial de la fuente agrícola procede junto con un cambio en la intensidad del flujo de energía de la sustancia, que se forma a partir del uso de técnicas de mejora La energía afecta el 
estado de recuperación de tierras (LRS) del paisaje agrícola. Tiene un impacto significativo en los indicadores integrales de riesgo de recursos. Para evaluar el estado de recuperación del paisaje agrícola, se ha desarrollado un indicador de riesgo crítico (IIR), un modelo de riesgo de recursos, que es un modelo de simulación y recursos, ya que combina varios indicadores cuantitativos de LRS con indicadores de riesgo adimensionales y determina el estado crítico del recurso. La base del programa informático contiene un modelo de riesgo de recursos IIR, que incluye indicadores de riesgo y la escala de seguridad de riesgo (SSR), que permite evaluar el potencial de recursos del paisaje agrícola. El modelo IIR se adapta a los recursos naturales de un paisaje agrícola real. La base del modelo son los riesgos de recursos LRS, con la ayuda de los cuales se lleva a cabo la gestión del estado de recuperación del paisaje agrícola. La optimización del indicador de riesgo integral para los recursos de taxa reduce el volumen de trabajo realizado por las técnicas de recuperación.

Palabras clave: paisaje agrícola, modelo, programa, manejo, estado de recuperación de suelos.

\section{INTRODUCTION}

Agriculture sufficiently provides the population with products in terms of quantity and quality on agricultural landscapes, which require continuous replenishment of soil fertility with modern adapted techniques that consume more and more energy resources (Kuznetsov et al., 2017; http://dx.doi.org). For example, precise technologies that form digital agricultural landscapes about the state of crops exposed to weeds ensure control over the introduction of pesticides, mineral fertilizers and serve also to combat pests and diseases in the fields do not provide an increase in the soil reclamation state. These techniques help to preserve the harvest and reduce the production cost. We should note, however, that a constant increase in the yield of agricultural crops over a period of 40-50 years in the black earth soils of the south of the Russian Federation has led to a decrease in humus content from 8 to 4-6\% (Zachary, 2020; Khitrov et al., 2015; Val'kov et al., 1995), while the yield of the same winter wheat increased from 3-5 to 6-7 t/ha and, similarly, the yield of other agricultural crops also increases. A paradox! It follows that the crop yield increases not only due to new varieties, fertilization and adapted technologies of precision farming but also due to increased mobilization of soil nutrients, which leads to the risks of a decrease in the reclamation state and soil fertility. The land reclamation state is improved mainly through the introduction of mineral and organic fertilizers (Kostenko, 2017; Yakovchenko \& Kosolapova, 2019; Dong et al., 2012). However, there are other manageable risks that lead to land reclamation $(L R S)$; these include degradation from water and air erosion; waterlogging and flooding; salinization and waterlogging of lands, which largely determine soil fertility. These risks can be attributed to the main group of manageable risks affecting the agroresource potential of agricultural landscapes, thus, no matter what adapted and precise technologies are used, the solution will result in one of three options: increasing the reclamation state of the agricultural landscape soils; the state of the agricultural landscape will not change; degradation will continue.

The objective of the research is to develop a resource model of the integral risk indicator IIR to improve the land reclamation state $L R S$, considering that the main risks that determine the quantitative $L R S$ of the agricultural landscape are resource risks. A method for managing the agroresource potential of agricultural landscapes ARPA with an integrated risk indicator IIR on a digital platform in the Google system. The risk safety scales $S S R$ are based on IIR. 


\section{METHODS}

The development of a digital agroresource potential management platform is based on the system of vectors of the Hilbert separable space, as it is assumed that there are countable total risks of taxa resources in space. It should be assumed that all orthonormal bases in the Hilbert space have the same cardinality, which allows us to define the dimension of the Hilbert space as the dimension of an arbitrary orthonormal basis (Gram et al., 2020). A Hilbert space is separable only if it has countable dimension. Risks are considered as countable vectors of the Hilbert space, and are considered linear combinations close to the norm, as elements of resource risk management. The resources are located on the platform in the form of a digital map in Google, which contains a vector separable space in the form of taxa with a coordinate system fixed on an electronic map.

To obtain information about the initial resource potential, monitoring of the agricultural landscape is used, which is divided into rectangular or triangular taxa, where the main risks of soil resources are studied at their vertices. Risks of resources in the arable horizon of the soil, affecting the LRS, are indicated through risk indicators, which are recorded on the Google electronic map. After the application of adapted technologies of precision farming or resource adapted technologies, monitoring is carried out on the same agrolandscape, where parameters are investigated at the same vertices of taxa, where the risk indicators were initially determined; a conclusion is made about the effectiveness of the selected techniques according to the integral risk indicator.

The land reclamation state determines the agroresource potential of the agricultural landscape. The agroresource potential can be controlled by the intensity of the energy flow of a substance, changes in the energy of a substance at the vertices of taxa: macroelements, humus, trace elements, and other elements in the soil before and after the application of reclamation techniques (Loaiza, 2017). Therefore, energy determines the reclamation state of the soils of the agricultural landscape and has a significant impact on the risks of resources. The higher the change in the intensity of the energy flow per unit of the agricultural landscape (taxon) is, the greater resource risks are.

We made the following assumptions when creating a resource model of risks of agroresource potential management: the taxon is represented by a vector, the energy component of the vector is determined by a finite number of indicators; at the vertex of the taxon, the instantaneous energy of the flow of matter changes under the influence of reclamation techniques; an integral risk assessment is adopted, considering the principle of additivity of the matter flow energy.

\section{RESULTS}

The energy of matter integrates changes in $n$ risks in space and in the duration of their action on the taxon's surface. The main properties of integral indicators of risks of taxon degradation are established. The risk of taxon degradation is considered adequate if all risk indicators are presented in dimensionless and relative weight form. The danger of taxon degradation increases linearly with a proportional increase in the weight of risks at the taxon vertices. At the top of the taxon, one integral energy flux of matter acts, i.e., at the top of the taxon, an integral risk indicator is determined. Taxa are considered to be IIR equivalent if the risk indicators are comparable in weight. For a critical integral risk indicator, a dimensionless value is taken, at which the stability of the integral risk indicator $L R S$ of agricultural landscapes is disturbed. 
The norm of a vector (taxon) is determined from the Holder norm of $n$-dimensional vectors by the formula:

$$
\|x\|_{p}=\left(\Sigma\left|x_{i}\right|^{p}\right)^{\frac{1}{p}}
$$

where $\|x\|$ is the norm of the element $x$ - vector space; $p$ is a natural number $(p \geq 1) ; x_{i}$ is the norm of an element of vector space or risk indicator corresponding to the norm of an element.

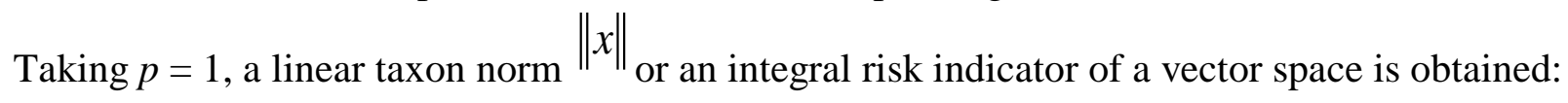

$$
\|x\|_{1}=\Sigma\left|x_{i}\right|
$$

With the simultaneous action of $n$ indicators, it follows from (2):

$$
I I R=\frac{1}{n} \sum_{n=1}^{n} I
$$

where IIR is an integral risk indicator showing the state of the agroresource potential of the agricultural landscape; $\sum_{i=1}^{n} I_{i}=I_{1}+I_{2}+\ldots+I_{n}$ is the sum of separate dimensionless indicators of $n$ risks. $I_{i}$ is a dimensionless risk indicator $\left(I_{i}=x_{i} ;\right.$;)

Risk management should proceed following the scheme of sustainable development of the agricultural landscape, when the integral indicator of risks tends to a minimum. Then, obviously, it follows from expression (3):

$$
I I R=\frac{1}{n} \sum_{n=1}^{n} I \rightarrow I I R_{\min }
$$

where $I I R_{\min }$ is the minimum integral risk indicator.

Expression (4) in the first approximation is considered as a resource model of an integral indicator of risks, which is considered in a formal form, when risks have fixed dimensionless values reduced to a single indicator; in this case, to a numerical dimensionless indicator that reflects the state of the resource. Therefore, on the right side of expression (4), the minimum indicator corresponds to the critical indicator, i.e. a critical indicator of risk, which, if exceeded, affects sustainable development of the agricultural landscape. Subject to the above, the risk model is as follows:

$$
I I R=\frac{1}{n} \sum_{n=1}^{n} I_{i} \leq K I I R,
$$

where KIIR is a critical integral risk indicator, which, if exceeded, causes an unstable position of the object.

Model (5) is imitation and resource one, as it combines various $L R S$ indicators with a set of dimensionless indicators that determine the critical state of the system. The model considers the state of the agricultural landscape resources and can be used in processing environmental monitoring data and control on the ARPA digital platform to improve the $L R S$ of agricultural landscapes. 
Agroresource potential of agricultural landscapes - agricultural land with the appropriate $L R S$, water and bioclimatic supply. $L R S$ is the state of the agricultural landscape, which must be assessed to make decisions on carrying out comprehensive land reclamation to increase ARPA.

$A R P A$ digital platform monitoring and management.

$A R P A$ is monitored by the integral risk indicator IIR:

- the object of research is agrolandscapes subject to degradation;

- on the Google electronic map, agricultural landscapes are divided into taxa and fixed with grid

lines;

- monitoring of agricultural landscapes by routing surveys, LRS indicators are determined at the vertices of taxa (macroelements, groundwater level and their mineralization, the degree of soil salinity, etc., which are necessary to complete the task);

- at the vertices of taxa of agricultural landscapes, integral indicators of risks IIR are calculated using the model (5);

- IIR are compared with a critical integral risk indicator $(K I I R)$. If $I I R<K I I R$, the system develops steadily. If $I I R \leq K I I R$, degradation of $L R S$ develops;

ARPA management through IIR.

- before the cultivation of crops, monitoring of agricultural landscapes by routing surveys, $L R S$ indicators are determined at the vertices of taxa, which are necessary to complete the task;

- the model (5) is used to calculate the IIR and compare it with the KIIR. If $I I R<K I I R$, the system develops steadily. If $I I R \geq K I I R$, degradation of $A R P A$ develops;

- an adapted resource technology is adopted to improve the $L R S$, depending on the degradation degree of ARPA taxa;

- the degree of degradation of taxa is established by risk indicators $\left(I_{i}\right)$;

- after cultivation of crops, monitoring is carried out, determined by (5) IIR.

- a conclusion is made about the techniques that were used in this field following the LRS;

- the adopted techniques are being adjusted or new techniques more effective in the agricultural landscape are being adopted.

Rationale for IIR indicators and safety risk scale (SSR) for ARPA digital platform management.

Each $L R S$ risk indicator determines the discrete state of $A R P A$ agricultural landscapes and has a dimension different from other indicators. For example, during irrigation reclamation, waterlogging of agricultural landscapes may occur due to the rise in the level of saline groundwater (risk of flooding) and cause secondary salinization of lands (risk of land salinization). Irrigation of crops with treated wastewater, on the one hand, is the rational use of water resources and saving fertilizers, and on the other hand, irrigation with poorly treated wastewater is a risk of soil pollution and degradation of agricultural landscapes. Man-made risks include insufficient wastewater treatment, uneven distribution of treated wastewater over the irrigated area, and inadequacy of irrigation equipment to operational requirements.

Consequently, the risks are ambiguous, have a different nature and energy, and are expressed in certain physical quantities. Therefore, to assess the $L R S$, the indicators must be brought to a single dimensionless (point) indicator of the risk measure. 
An integral risk indicator is formed to eliminate ongoing or anticipated land degradation. The number of $L R S I_{i}$ depends on the degree of detail, the objective of the research, and the techniques used.

To protect agricultural landscapes from degradation according to $I I R, 11 I_{i}$ were established (Loaiza, 2017). These include indicators: the mechanical composition of the arable soil layer - $I_{1}$; availability of mobile $I_{2}$; availability of mobile phosphorus - $I_{3}$; availability of hydrolyzable nitrogen - $I_{4}$; humus content - $I_{5}$; acid-base balance of the soil $(p H)$ - $I_{6}$; the degree of soil salinity - $I_{7}$; groundwater level in the agricultural landscape - $I_{8}$; water-air condition of the soil - $I_{9}$; the flooded area of the agricultural landscape $-I_{10}$; and mineralization of groundwater $-I_{11}$.

Indicators $\left(I_{1}-I_{8}\right)$ are used to monitor and control the increase in the $L R S$ of the arable soil horizon, and indicators $\left(I_{6, I_{8}}-I_{11}\right)$ are used to eliminate flooding and waterlogging of agricultural landscapes.

Each ARPA condition is graded by the IIR on the SSR. To assess ARPA according to the integral indicator of risks $I I R$, the SSR was developed (Table).

Table 1. Safety risk scale (SSR) according to IIR

\begin{tabular}{|c|c|c|}
\hline $\begin{array}{c}\text { Integral risk indica- } \\
\text { tor intervals }\end{array}$ & $\begin{array}{c}\text { Characteristics of the agricultural } \\
\text { landscape }\end{array}$ & $\begin{array}{c}\text { Agricultural landscape scor- } \\
\text { ing }\end{array}$ \\
\hline$I I R=1$ & No risk & "perfect" \\
\hline $1<I I R \leq 2$ & $\begin{array}{c}\text { Agricultural landscape is not subject } \\
\text { to risks }\end{array}$ & "good" \\
\hline $2<I I R \leq 3$ & Unstable agricultural landscape & "satisfactory" \\
\hline $3<I I R \leq 4$ & $\begin{array}{c}\text { Agricultural landscape in critical } \\
\text { state }\end{array}$ & "unsatisfactory" \\
\hline$I I R>4$ & Agricultural landscape is degrading & "disaster" (degradation) \\
\hline
\end{tabular}

For the "perfect" state, the risk measure is estimated as $I I R=1.0$. At $1<I I R i \leq 2$, the state corresponds to "good". In a satisfactory condition, the risk measure is in the range $2<I I R \leq 3$. At 3 $<I I R \leq 4$ - the agricultural landscape is characterized by an unsatisfactory state (the agricultural landscape is degrading) and at IIR $>4.0$ - degradation (disaster).

The model (5) determines the mathematical expectation of damage to the IIR resource, which may be in a particular $S S R$ interval. Analyzing the data in the table, we can state that the critical KIIR is $I I R=2.0$, which, if exceeded, causes an unstable satisfactory state of ARPA.

Agricultural landscapes of the Krasnodar Territory on a large territory are caused by flooding and waterlogging. Studies show that the degradation of agricultural land from flooding and waterlogging leads to a loss of yield up to 20-30\% (Kuznetsov et al., 2018). When the level of mineralized groundwater rises to the surface, secondary salinization is provided for the soils. This process is observed in agricultural landscapes with a high groundwater table, but most often it is observed during irrigation of agricultural crops. Therefore, $A R P A$ management needs to regularly monitor the $L R S$ of the irrigated projects. 
The results of checking the ARPA management model are presented on soils of the Krasnodar Territory degraded from flooding. The ARPA management is based on a digital model of the resource state of the agricultural landscape, including control components - SSR and IIR. The method uses the resource "agrolandscape-technology" model and addresses the problem of eliminating flooding (waterlogging) of agrolandscapes.

Stages of ARPA management:

1). A digital assessment of the soil reclamation state is carried out according to IIR on an electronic map for taxa. The size of taxa depends on the required accuracy and detail of ARPA monitoring. 2). Soil of the studied horizons is sampled at the tops of the squares; the depth of the groundwater level is established. The results of studies of soil samples are processed according to IIR and sent through Google systems, global positioning systems (GPS), etc. to the control panel.

3 ). The information is displayed on the reclamation digital electronic map of the agricultural landscape. For this, computer programs are used.

4) Each taxon point is displayed in the global positioning system, and its coordinates are automatically entered into the program.

5). The digital reclamation map shows the level and salinity of groundwater; acid-base balance of the soil; the content of macronutrients and soil humus; the mechanical composition of the soil; the degree of soil salinity. Risks allow assessing the $L R S$.

6). The program displays plots on a digital map with information on the $L R S$ indicated in the vertices of taxa, which determines the degree of land degradation according to IIR to make decisions on the management of reclamation regimes using resource-saving adapted techniques.

7). The program includes a selection of adapted standard situations that simulate flooding and waterlogging of agricultural landscapes, and the corresponding resource-saving adapted techniques and sets of reclamation machines for work.

An example of digital ARPA management. An 82.39 ha field is represented, where the distance between the tops of taxa was taken in the range of 80-100 $\mathrm{m}$. The file of the digital reclamation map of the agricultural landscape is saved in the format (*.html) and is located in the folder together with the program. The digital resource model makes it possible to quickly predict the LRS.

The parameters of the agricultural landscape model are fixed at each point of the electronic map with GPS coordinates. The coordinates of taxa points display and compare IIR with the critical KIIR value.

The resulting situation on the digital reclamation map reflects the real state of the agricultural landscape at the first stage (Figure 1). The digital model displays the areas of the landscape with the integral indicator $I I R$, which separates taxa by $L R S$ on the reclamation map, where (0-1...3-4) are MSP indicators: - green (0-1) - good; - yellow (1-2) - satisfactory; - blue (2-3) - unsatisfactory; - red (3-4) - disaster (degradation).

The digital ARPA model sets the input parameters that determine the LRS of the agricultural landscape, the contours and sizes of areas that need to use resource-saving adapted technologies to improve the $L R S$. For visual display of $A R P A$, Google is used - an electronic map that shows the 
points of soil sampling with the number and the integral indicator $L R S$. The Google electronic resource map displays the tops of the squares where the samples were taken. The results of processing field studies using a resource risk model and a computer program are displayed on the screen. The map helps to analyze the situation on the field for making decisions on replenishing the resource of the agricultural landscape, depending on the extent of land degradation from flooding and waterlogging according to IIR digital indicators.

The developed computer program uses the loaded map to simulate the resource boundaries of taxa indicating the size of the areas according to the corresponding assessments of the digital scale of risk safety. The result is a digital ARPA model (Figure 1).

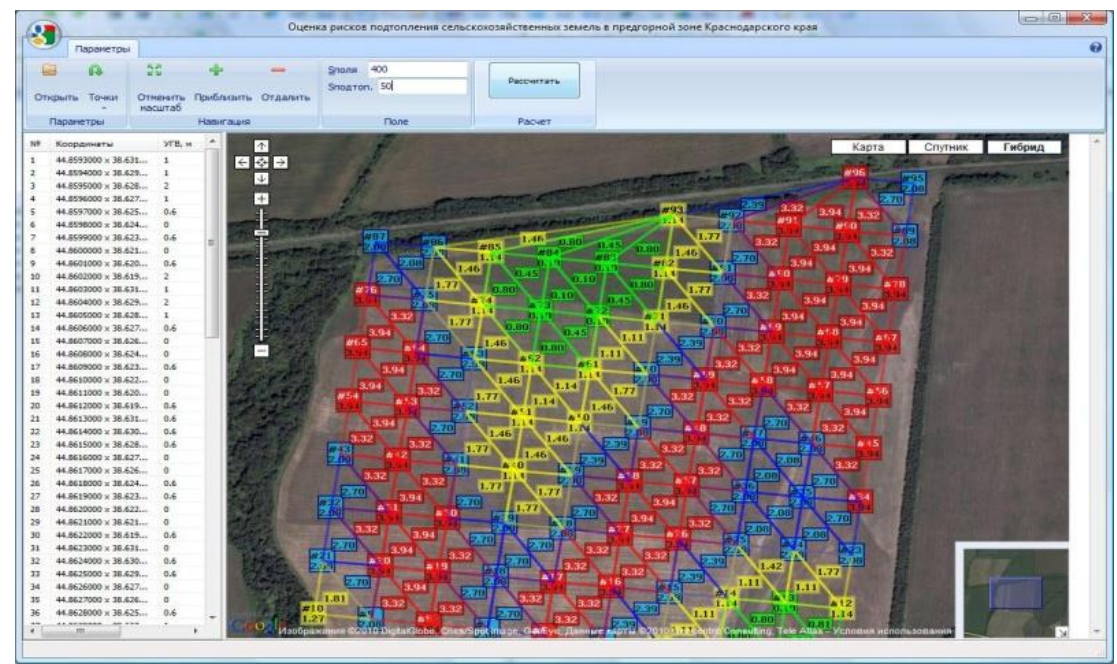

Figure 1. The digital ARPA model

In terms of $I I R$, the area of a good and satisfactory field accounts for $32.8 \%$ of the total area of the agricultural landscape, the rest of the area (67.2\%) needs a set of works to restore ARPA using resource adapted technologies and a complex of reclamation machines.

To use resource-saving adapted technologies for protecting land from flooding a digital model in this form will require a large amount of resources. Therefore, the next step is necessary to average the contours of the areas of sites to perform technological operations for standard schemes of flooding and waterlogging of lands.

The Delaunay triangulation method is used to average the dimensions of the contours of the areas by IIR using SSR. The program automatically averages the contours of the areas, with the required accuracy of the assessment of degraded landscapes. At the initial stage, 4 contours of the $S S R$ averaged medium were established. To reduce the scope of work and the number of sets of reclamation machines, four environments are combined into two averaged environments with conditionally the same $L R S$ according to IIR (Figure 2).

For the restoration of the LRS agricultural landscape from degradation, resource adapted technologies are selected for two ARPA environments. For a satisfactory ARPA, the field area bounded by a yellow outline, a set of resource adapted technologies and a set of machines are needed to lower the groundwater level and apply calcium ameliorants. The red-outlined area of the field needs a 
set of techniques and a set of machines that will provide radical land reclamation to restore agricultural landscapes from degradation, including measures to remove excess water at high costs in terms of $L R S$. Further, it is necessary to ensure the choice of 2, not 4 complexes of the reclamation sets of machines for the recovery of $L R S$, depending on the complexity of the relief and morphology of the sites.

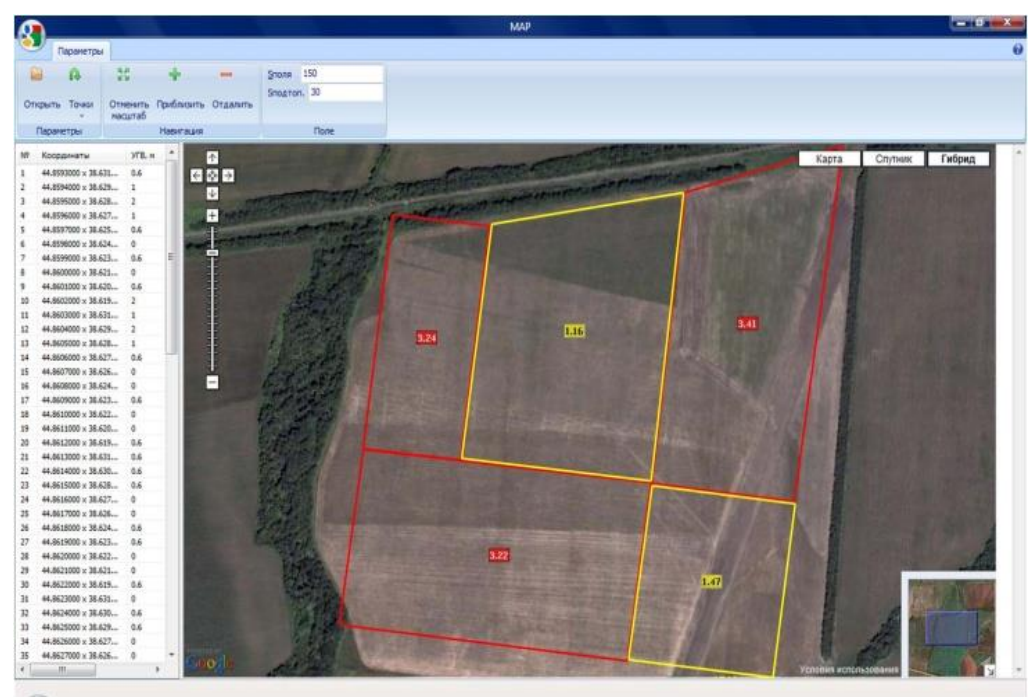

Figure 2. LRS digital recovery solution

\section{CONCLUSION}

We determined the energetic properties of integral assessments of the degradation hazard of the taxon of the agricultural landscape. The assessment of the risk of taxon degradation increases linearly with a proportional increase in the risk weight at the taxa vertices. At the top of the taxon, the energy flux of the substance acts, which is determined by the integral index of risks IIR. The smaller the taxon size is, the more reliable the $L R S$ information is.

We developed a resource model of risks $I I R$, which is imitation and resource, as it combines various quantitative $L R S$ indicators with a set of dimensionless risk indicators that determine the critical state of the system. The IIR model considers the state of the agricultural landscape resources and can be used in processing environmental monitoring data and managing the $L R S$ increase on the ARPA digital platform.

We developed a method for managing agroresource potential using an IIR resource risk model on digital platforms to obtain information on the reclamation state of taxa and the agricultural landscape in general. At the vertices of taxa, the resource state is determined according to IIR to make decisions on the use of resource adapted techniques and a set of machines to improve the $L R S$ of the agricultural landscape.

The developed scale of safety risks SSR is used to plan risks in the cultivation of agricultural crops by limiting indicators, and perform a quantitative assessment of $L R S$ when managing the agroresource potential of agrolandscapes. 
The computer program base contains a digital risk model IIR, including risk indicators and SSR, which makes it possible to assess the resource state of the agricultural landscape by the reclamation state of the LRS soils. The digital IIR model is adapted to the natural resources of a real agricultural landscape. The basis of the model is the resource risks, with the help of which the management of the reclamation state of the agricultural landscape is carried out. Optimization of the integral risk indicator for taxa resources reduces the volume of work on $A R P A$ agricultural landscapes, and also reduces the costs of restoring the $L R S$.

\section{CONFLICT OF INTEREST}

The authors confirm that the information provided in the article does not contain a conflict of interest.

\section{REFERENCES}

Barsukova, G. N., Yurchenko, K. A., \& Derevenets, D. K. (2020, July). Prospects of Agricultural Land Use in Krasnodar Territory in Respect to Territorial Features. In International Conference on Policicies and Economics Measures for Agricultural Development (AgroDevEco 2020) (pp. 420-424). Atlantis Press.

Dong, W., Zhang, X., Wang, H., Dai, X., Sun, X., Qiu, W., et al. (2012). Effect of Different Fertilizer Application on the Soil Fertility of Paddy Soils in Red Soil Region of Southern China. PLoS ONE, 7(9), e44504. doi:10.1371/journal.pone.0044504.

Gram, G., Roobroeck, D., Pypers, P., Six, J., Merckx, R., \& Vanlauwe, B. (2020). Combining organic and mineral fertilizers as a climate-smart integrated soil fertility management practice in sub-Saharan Africa: A meta-analysis. PLoS ONE, 15(9), e0239552. https://doi.org/10.1371/journal.pone.0239552.

http://dx.doi.org/10.14505/jemt. - 78-83 p.

Khitrov, N.B., Vlasenko, V.P., Rukhovich, D.I., Bryzzhev, A.V., Kalinina, N.V., \& Rogovneva, L.V. (2015). The geography of Vertisols and Vertic soils in the Kuban-Azov Lowland. Eurasian Soil Science, 48, 671-688.

Kostenko, I.V. (2017). Relationships between parameters of the humus status of forest and meadow soils and their altitudinal position on the main Crimean range. Eurasian Soil Sc, 50, 515-525. https://doi.org/10.1134/S1064229317050088

Kuznetsov, E. V., Khadzhidi, A. E., Kilidi, K. I., \& Kurtnezirov, A. N. (2018). Management of agro-resource potential for agricultural landscape stability increase. Plant Archives, 18(2), 2151-2158.

Kuznetsov, E.V., Safronova, T. I., Sokolova, I. V., Khadhidi, A. E., \& Gumbarov, A. D. (2017). Development of a Land Resources Protection Model. Journal of Environmental Management and Tourism Biannually / Volume VIII. Issue 1(17). SPRING. ISSN 2068 - 7729. Journal DOI

Loaiza, M. (2017, May). A short introduction to Hilbert space theory. In Journal of Physics: Conference Series (Vol. 839, No. 1, p. 012002). IOP Publishing.

Val'kov, V.F., Shtompel', Yu. A., Trubilin, I.T., Kotlyarov, N.S., \& Solyanik, G.S. (1995). Soil of Krasnodar Krai: Use and Protection (North Caucasus Scientific Center, Rostov-on-Don) [in Russian].

Yakovchenko, M., \& Kosolapova, A. (2019). Reproduction of soil fertility: research of physical and chemical characteristics of soils. XII International Scientific Conference on Agricultural Machinery Industry IOP Conf. Series: Earth and Environmental Science 403, 012036 IOP Publishing doi:10.1088/1755-1315/403/1/012036.

Zachary, P. (2020). Stewart, Gary M. Pierzynski, B. Jan Middendorf and P. V. Vara Prasad. Approaches to improve soil fertility in sub-Saharan Africa. Journal of Experimental Botany, 71(2), 632-641, doi:10.1093/jxb/erz446. 